\title{
Accuracy of Ultrasound in the Evaluation of Pediatric Abdominal Surgical Emergency: A Comparison with Intra-Operative Findings
}

\author{
Chukwubuike Kevin Emeka \\ Department of Surgery, Enugu State University Teaching Hospital, Enugu, Nigeria
}

\section{Email address:}

chukwubuikeonline@yahoo.com

\section{To cite this article:}

Chukwubuike Kevin Emeka. Accuracy of Ultrasound in the Evaluation of Pediatric Abdominal Surgical Emergency: A Comparison with Intra-Operative Findings. Advances in Surgical Sciences. Vol. 8, No. 1, 2019, pp. 1-4. doi: 10.11648/j.ass.20200801.11

Received: December 12, 2019; Accepted: December23, 2019; Published: January 6, 2020

\begin{abstract}
Background: Pediatric abdominal surgery emergency (PASE) is a frequent reason for emergency admission and surgery in children. PASE is a significant cause of morbidity and mortality especially in developing countries and it constitutes a significant workload of the pediatric surgeon. Ultrasound is available, affordable and accessible in most centers. Though ultrasound is operator dependent, its evaluation of children who have abdominal symptom plays a central role in surgical decision making. Methodology: We evaluated the medical records of all the consecutive children who presented with abdominal symptoms, had abdominal ultrasound and were operated upon between October 2017 and March 2019. This study was carried out in a teaching hospital in Enugu, Nigeria. We compared the ultrasound reports and intraoperative findings; and determined the extent of accuracy of the ultrasound report. Results: One hundred and forty seven children were retrospectively analyzed. There was male dominance and abdominal pain was the predominant presenting symptom. The mean age of the patients at presentation was 6 years. All the patients had abdominal ultrasound and the overall accuracy of ultrasound was $65.8 \%$. Intussusception is the disease condition that had the highest level of ultrasound accuracy. Most of the patients (93.2\%) did well and were discharged home. There were 10 deaths accounting for $6.8 \%$ of the patients. Conclusion: Abdominal ultrasound is reliable and fairly accurate in the evaluation of children who have abdominal disease conditions.
\end{abstract}

Keywords: Pediatric, Abdominal, Accuracy, Ultrasound, Emergency

\section{Introduction}

Pediatric abdominal surgical emergency (PASE) constitutes a significant workload of the pediatric surgeon. PASE is a frequent reason for emergency admission of children and it accounts for $2.4-3.1 \%$ of all pediatric admissions in Nigeria [1]. Mhando and his colleagues in 2008 reported that pediatric abdominal surgical emergencies accounted for up to $4 \%$ of all pediatric admissions in Tanzania [2]. The range of pediatric abdominal surgical emergencies represents a diverse spectrum of conditions, from congenital to acquired pathologies [2]. PASE poses a diagnostic challenge to the clinician due to inability of the children to explain their symptoms and co-operate during physical examination [3]. Abdominal radiographs have been used for the evaluation of children who have PASE. However, the diagnostic yield of plain radiograph is limited due to its low sensitivity and high non-specificity [4]. Ultrasound has been used for evaluating acute abdominal conditions since its use by Puylaert in 1986 when he described graded compression during ultrasound examination for the diagnosis of acute appendicitis [5]. Ultrasound is an essential imaging modality especially in children because it is non-invasive, cost effective and does not expose the child to radiation. It is as good as laparoscopy and can be used in patients with a scarred abdomen. Ultrasound can also be done on the patient's bedside [6-9]. The end point of this study was to verify the accuracy of ultrasound imaging in the evaluation of abdominal surgical emergency in children, with respect to the intra-operative findings. 


\section{Methodology}

This was a retrospective study of pediatric patients who had surgery for abdominal surgical emergency. This study covered an 18-months period (October 2017 to March 2019). All patients from birth to the age of 16 years who presented to the pediatric surgery unit of Enugu State University Teaching Hospital (ESUTH), Enugu, Nigeria were evaluated for this study. ESUTH is a tertiary hospital located in Enugu, South East Nigeria which according to the 2016 estimates of the National Population Commission and Nigerian National Bureau of Statistics, has a population of about 4 million people and a population density of $616.0 / \mathrm{km}^{2}$.

All the patients had abdominal ultrasonography preoperatively using commercially available, real time scanner with 5-MHz linear transducer (TITAN; Sonosite Inc, Bothell, WA, USA). The ultrasonography was done by consultants and residents in the department of radiology of the hospital. The results of the ultrasonography were compared with the intra-operative findings which were documented in the operation notes. The surgeries were performed by pediatric surgeons.

Patients who had surgery at a peripheral hospital for the condition before being referred to us for reoperation were excluded from the study. Patients who were managed nonoperatively and patients with pathologies that required histological confirmation were also excluded from the study. Data were extracted from the case notes, operation notes, operation register, and admission-discharge records. The information extracted included age, gender, clinical presentation, duration of symptoms before presentation, duration between presentation and intervention, ultrasound result, intra-operative finding at surgery, duration of hospital stay and outcome. Ethical approval was obtained from the Ethics and Research committee of ESUTH. Statistical Package for Social Science (SPSS) version 21 was used for data entry and analysis. Data were expressed as percentages, mean and range.

\section{Results}

\subsection{Patients' Demography}

One hundred and fifty seven pediatric abdominal surgical emergency cases were seen during the study period but only 147 patients had complete case records and formed the basis of this report. There were 119 males and 28 females, with a male to female ratio of $4.25: 1$. The mean age of the patients at presentation was 6 years (range: 2 days -16 years). The mean duration of symptoms before presentation to the hospital was 3.5 days (1-10 days). The mean duration between presentation and intervention was 1.8 days (1-3 days). The mean duration of hospital stay was 6.7 days (2-14 days), as shown in Table 1.

Table 1. Demographic profile of the patients.

\begin{tabular}{ll}
\hline Gender & \\
\hline Male & $119(81 \%)$ \\
Female & $28(19 \%)$ \\
Mean age of the patients & 6 years \\
Mean duration of symptoms before presentation & 3.5 days \\
Mean duration between presentation and intervention & 1.8 days \\
Mean duration of hospital stay & 6.7 days \\
\hline
\end{tabular}

\subsection{Clinical Presentation}

Abdominal pain was the most common predominant presenting symptom. Others are shown in Table 2.

Table 2. Predominant presenting symptoms of the patients.

\begin{tabular}{lll}
\hline Presenting Symptoms & Number & Percentage \\
\hline Abdominal pain & 74 & 50.4 \\
Bilious Vomiting & 39 & 26.5 \\
Constipation & 30 & 20.4 \\
Abdominal distension & 4 & 2.7 \\
\hline
\end{tabular}

\subsection{Relationship Between Definitive Diagnosis and Diagnosis at Ultrasound}

The overall accuracy of ultrasound in evaluating pediatric abdominal surgical emergency was $65.8 \%$. Details of the correct and incorrect ultrasonographic results are shown in Table 3.

Table 3. Correlation between intra-operative (definitive) diagnosis and ultrasonographic diagnosis.

\begin{tabular}{llll}
\hline \multirow{2}{*}{ Definitive diagnosis at Surgery } & Number of cases & Preoperative ultrasonographic diagnosis & Correct (\%) \\
\cline { 2 - 4 } & & $50(89.3)$ & $6(10.7)$ \\
Intussusception & 56 & $20(66.7)$ & $10(33.3)$ \\
Typhoid intestinal perforation & 30 & $15(75.0)$ & $5(15.0)$ \\
Obstructed external hernias & 20 & $10(58.8)$ & $7(41.2)$ \\
Appendicitis & 17 & $7(70.0)$ & $3(30)$ \\
Abdominal trauma & 10 & $3(50)$ & $2(30)$ \\
Neonatal intestinal obstruction & 6 & $4(66.7)$ & $1(50)$ \\
Ruptured appendix & 6 & 2 & $1(50)$ \\
Adhesive bowel obstruction & 2 &
\end{tabular}

\subsection{Outcome}

Most of the patients $(93.2 \%)$ did well and were discharged home. There were 10 deaths accounting for $6.8 \%$ of the patients.

\section{Discussion}

Zero radiation to children, quick, more efficient and easy access make ultrasound one of the leading choices in the evaluation of pediatric abdominal surgical emergency, as 
compared to computed tomography (CT) scan or magnetic resonance imaging (MRI) [10].

In the present study, ultrasound was found to be accurate in evaluating children who had abdominal emergencies in $65.8 \%$ of the patients. This is in agreement with the finding of Aviral et al [4]. Mendelson et al and Walsh et al in their separate studies reported ultrasound to be $50 \%$ diagnostic in the evaluation of children who have acute abdomen [11, 12]. In adults, the diagnostic accuracy of ultrasound has been reported to be between $25 \%$ and $34.7 \%[6,7,13]$. The thinner abdominal wall of children and the type of frequency probe used may explain this difference in diagnostic accuracy [4].

Ultrasound has a high predictive value for intussusception. Eighty nine percent accuracy rate recorded in the present study is consistently reported by other studies [14 - 16]. However, Usang et al, in their study of ultrasound in pediatric intussusception, reported a low specificity of $50 \%$. The authors explained that this low specificity value could be due to inexperience of the private sonographers who did the initial ultrasound before referring the patients to the tertiary centre [14].

Ultrasound done for typhoid intestinal perforation detects free intra-peritoneal fluid collections but this is non-specific for typhoid intestinal perforation. Chalya et al found free intraperitoneal fluid in $85.7 \%$ of their patients which is at variance with our finding of $66.7 \%$. This difference may be explained by the different levels of experience of the sonographer and non-specificity of the finding of free intra-peritoneal fluid in typhoid intestinal perforation. The diagnosis of obstructed hernia is always clinical. Ultrasound examination may be required if physical findings are inconclusive or in cases of acute scrotum [18]. Ultrasound can also be used in assessing peristalsis, wall thickness and vascularity of the bowel in the hernia sac [19]. Chen et al reported that ultrasound is $95.5 \%$ accurate in detecting inguinal hernia in boys [20]. However, we recorded $75 \%$ accuracy in the present study. The reason for this is not clear but may be explained by the level of expertise of the sonographer.

Appendicitis was the fourth most common cause of pediatric abdominal emergency in our series. But the diagnostic accuracy of ultrasound was only $58.8 \%$. This finding is inconsistent with the report of other researchers [5, 21]. However, our finding is in line with the report of Khalid et al [22]. The reason for these differences may be due to the fact that most of our patients who had appendicitis presented at odd hours and the ultrasound scan was done by resident doctors on call.

The use of ultrasound for abdominal trauma was first described by Kristensen and colleagues in 1971 [23]. Our accuracy level of $70 \%$ is unsupported by the reports of previous workers. Ndour et al and Tiling et al reported an accuracy rate of ultrasound for trauma above $90 \%[24,25]$. Radwan et al reported that ultrasound may miss up to $25 \%$ of intra-abdominal injury and the results of abdominal ultrasound depend on the ultrasound machine, the patient and the operator [26].

Prenatally, neonatal intestinal obstruction may be suggested by the presence of polyhydramnios and dilated loops of bowel. The accuracy rate of ultrasound detecting intestinal atresia varies widely from $25 \%$ to $90 \%$ [27]. We observed an accuracy rate of $50 \%$ in the present study. With regards to ruptured appendix, our finding, in the current study, is similar to that of Blank et al [28]. Ruptured appendix reduces the accuracy of ultrasound diagnosis. This may be due to patient's lack of cooperation with ultrasound procedure due to pain [28].

The accuracy of ultrasound in detecting adhesive bowel obstruction in the current study is similar to the reports of Jang and associates [29]. However, most patients who present with features suggestive of bowel obstruction undergo abdominal radiograph largely because radiographs are widely available, inexpensive and accurate for diagnosing adhesive bowel obstruction [29].

\section{Conclusion}

One hundred and forty seven cases of children who were operated upon for abdominal surgical emergency over 18months period were evaluated for ultrasound accuracy. There were more males. Abdominal pain was the most common predominant presenting symptom. The overall accuracy of ultrasound in evaluating pediatric abdominal surgical emergency was $65.8 \%$ and intussusception had the highest level of ultrasound accuracy of $89.3 \%$. Most of the patients $(93.2 \%)$ did well while there were 10 deaths accounting for $6.8 \%$ of the patients. Abdominal ultrasound is reliable and fairly accurate in the evaluation of children who have abdominal pathologies.

\section{References}

[1] Adejuyigbe O, Fashakin EO. Acute intestinal obstruction in Nigerian children. Trop Gastroenterol. 1989; 10: 33-40.

[2] Mhando S, Young B, Lakhoo K. The scope of emergency paediatric surgery in Tanzania. Pediatr Surg Int. 2008; 24: 219-222.

[3] Abdur-Rahman LO, James OA, Adejuyigbe O. Paediatric surgical abdominal emergencies in a north central Nigerian centre. Annals of Pediatr Surgery. 2012; 8: 25-28.

[4] Aviral, Chana RS, Ibne Ahmad. Role of ultrasound in the evaluation of children with acute abdomen in the emergency set-up. J Indian Assoc Pediatr Surg. 2005; 10 (1): 41-3.

[5] Puylaert JB Acute appendicitis: ultrasound evaluation using graded compression. Radiology. 1986; 158 (2): 355-60. doi: 10.1148/radiology.158.2.2934762.

[6] Verbanck JJ, Van Aeist F, Rutgeerts, Demuynck H, Ghillebert G, Vergauwe P, Tytgat H, Segaert M. The impact of routine admission abdominal sonography on patient care. J Clin Ultrasound. 1988; 16 (9): 651-4. doi: 10.1002/jcu.1870160906.

[7] Lerch MM, Riehl J, Buechsel R, Kierdorf H, Winkeltau G, Matern S. Bedside ultrasound in decision making for emergency surgery: Its role in medical intensive care patients. Am J Emerg Med. 1992; 10 (1): 35-8. doi: 10.1016/07356757(92)90122-e. 
[8] Gupta H, Dupuy DE. Advances in imaging of the acute abdomen. Surg Clin North Am. 1997; 77: 1245-63.

[9] Simeone JF, Novelline RA, Ferrucci JT, Deluca SA, McCabe CJ, Mueller PR, Hall DA, Hall DA, Wittenberg J, Butch RJ et al. Comparison of sonography and plain films in evaluation of acute abdomen. Am J Roent. 1985; 144: 49-52.

[10] Partain KN, Patel AU, Travers C, Short HL, Braithwaite K, Loewen J, Heiss KF, Raval MV. Improving ultrasound for appendicitis through standardized reporting of secondary signs. J Pediatr Surg. 2017; 52 (8): 1273-79. doi: 10.1016/j.jpedsurg.2016.11.045.

[11] Mendelson RM, Lindsell DR. Ultrasound examination of the paediatric 'acute abdomen': preliminary findings. Br J Radiol. 1987; 60: 414-6. doi: 10.1259/0007-1285-60-712-414.

[12] Walsh PF, Crawford D, Crossling FT, Sutherland GR, Negrette JJ, Shand J. The value of immediate ultrasound in acute abdominal conditions. A critical appraisal. Clin Radiol. 1990; 42: 47-9. doi: 10.1016/s0009-9260(05)81622-8.

[13] Carmody E, McGrath EF, Keeling F. The role of emergency ultrasonography in the management of acute abdomen. Proceedings of the British Medical Ultrasound Society. 1990; 63: 383 .

[14] Usang UE, Inah GB, Inyang AW, Ekabua AT. Intussusception in Children: Comparison between ultrasound diagnosis and operation findings in a tropical developing country. Afr J Paediatr Surg. 2013; 10: 87-90.

[15] Eshed I, Gorenstein A, Serour F, Witzling M. Intussusception in Children. can we rely on screening performed by junior residents? Pediatr Radiol. 2004; 34 (2): 134-7. doi: 10.1007/s00247-003-1089-0.

[16] Verschelden P, Filiatrault D, Garel L, Grignon A, Perreault G, Boisvert J, Dubois J. Intussusception in Children: Reliability of ultrasound in diagnosis-A prospective study. Radiology. 1992; 184 (3): 741-4. doi: 10.1148/radiology.184.3.1509059.

[17] Chalya PL, Mabula JB, Koy M, Kataraihya JB, Jaka H, Mshana SE, Mirambo M, Mchembe MD, Gliti G, Gilyoma JM Typhoid intestinal perforations at a University teaching hospital in Northernwestern Tanzania: A surgical experience of 104 cases in a resource-limited setting. World J Emerg Surg. 2012; 7: 4. doi: 10.1186/1749-7922-7-4.

[18] Meena D, Jhuria R, Saxena S, Saini U. Inguinoscrotal hernia in infants: Three case reports in ultrasound diagnosis. Indian J Radio Imaging. 2017; 27 (1): 78-81. doi: 10.4103/0971-3026202951.
[19] Gale HI, Gee MS, Westra SJ, Nimkin K. Abdominal ultrasonography of the pediatric gastrointestinal tract. World J Radiol. 2016; 8 (7): 656-67. doi: 10.4329/wjr.v8.i7.656.

[20] Chen KC, Chu CC, Chou TY, Wu CJ. Ultrasonography for inguinal hernia in boys. J Pediatr Surg. 1998; 33 (12): 1784-7. doi: 10.1016/s0022-3468(98)90284-6.

[21] Janitz E, Naffaa L, Rubin M, Ganapathy SS. Ultrasound Evaluation for Appendicitis Focus on the Pediatric Population. A Review of the Literature. J Am Osteopath Coll Radiol. 2016; 5 (1): 5-14.

[22] Khalid M, Redhu N, Nazir B, Khalid S, Chana RS, Jha A. Diagnostic value ultrasonography in evaluation and management of acute abdominal conditions in the paediatric age group. Afr J Peaditr Surg. 2012; 9: 198-201.

[23] Kristensen JK, Buemann B, Keuhl E. Ultrasonic scanning in the diagnosis of splenic haematomas. Acta Chir Scand. 1971; 137: $653-7$.

[24] Ndour O, Camara S, Tendart V, Fall AL. Gassama F, Mbaye PA, Ndoye NA, Diouf C, Fall M, Ngom G. Blunt abdominal trauma in child: Epidemiology, diagnostic, and therapeutic analysis of 55 cases. Afr J Trauma. 2017; 6: 11-8.

[25] Tiling T, Boulion B, Schmid A. Ultrasound in blunt abdomino-thoracic trauma. In. Border, Allgoewer M, Hanson ST, editors. Blunt multiple trauma: comprehensive pathophysiology and care. New York: Marcel Decker; 1990. P 415-33.

[26] Radman MM, Abu-Zidan FM. Focussed Assessment Sonograph Trauma (FAST) and CT scan in blunt abdominal trauma: surgeon's perspective. Afr Health Sci. 2006; 6 (3): 187-190.

[27] Virgone C, D’antonio F, Khali A, Jonh R, Manzoli L, Giuliani S. Accuracy of prenatal ultrasound in detecting jejunal and ileal atresia: systemic review abd meta-analysis. Ultrasound Obstet Gynecol. 2015; 45: 523-29. doi: 10.1002/uog.14651.

[28] Blank W, Braun B. Sonography in the diagnosis of appendicitis - a prospective study. Z Gastroenterol. 1988; 62 (6): 573-8.

[29] Jang TB, Schindler D, Kaji AH. Bedside ultrasonography for the detection of small bowel obstruction in the emergency department. Emerg Med J. 2011; 28 (8): 676-8. doi: 10.1136/emj.2010.095729. 